TI 2011-047/ 1

Tinbergen Institute Discussion Paper

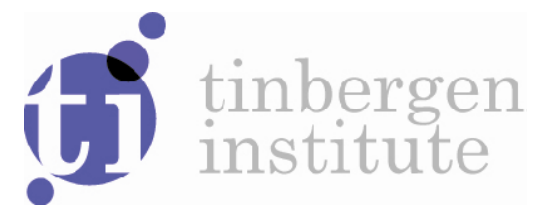

\title{
Balancing the Bids, Solutions for Unit Price Auctions
}

Sander Renes

Erasmus School of Economics, Erasmus University Rotterdam, and Tinbergen Institute. 
Tinbergen Institute is the graduate school and research institute in economics of Erasmus University Rotterdam, the University of Amsterdam and VU University Amsterdam.

More TI discussion papers can be downloaded at http://www.tinbergen.nl

Tinbergen Institute has two locations:

Tinbergen Institute Amsterdam

Gustav Mahlerplein 117

1082 MS Amsterdam

The Netherlands

Tel.: +31(0)205251600

Tinbergen Institute Rotterdam

Burg. Oudlaan 50

3062 PA Rotterdam

The Netherlands

Tel.: +31(0)10 4088900

Fax: +31(0)104089031

Duisenberg school of finance is a collaboration of the Dutch financial sector and universities, with the ambition to support innovative research and offer top quality academic education in core areas of finance.

DSF research papers can be downloaded at: http://www.dsf.nl/

Duisenberg school of finance

Gustav Mahlerplein 117

1082 MS Amsterdam

The Netherlands

Tel.: +31(0)20 5258579 


\title{
Balancing the Bids,
}

\section{solutions for unit-price auctions*}

\author{
Sander Renes \\ Erasmus School of Economics and Tinbergen Institute \\ email: srenes@ese.eur.nl
}

Februari 2011

\begin{abstract}
Many organizations use procurement tenders to buy large amounts of goods and services. Especially in the public sector the use of these reverse auctions has grown rapidly over the past decades. For the (reverse) unit price auction experience as well as theory have shown that they can attract skewed/unbalanced bids, i.e. bids where the price structure is distorted to take advantage of estimation errors. This paper shows that by either allowing for some secrecy or post tender competition, incentives in unit price auction change in such a way that can make bid skewing disappear.
\end{abstract}

Keywords: unit price auctions, procurement, skewed bids, unbalanced bidding, post tender competition, split award auction

*I would like to thank seminar audiances at the Erasmus University Rotterdam and the Tinbergen Institute and especialy Bauke Visser, Emiel Maasland and Sander Onderstal for their questions and remarks. The author gratefully acknowledges financial support from the Netherlands Orginasation for Scientific Research (NWO). 


\section{Introduction}

An increasing amount of organizations is using auctions to procure large amounts of goods and services. The European Union, for instance, estimated that, within the EU, governments and EU agencies alone procured for $€ 1500$ billion worth in goods and services, or $16 \%$ of EU GDP in $2002^{1}$. This is no coincidence since EU rules specify that any procurement above certain thresholds has to be done trough some type of tender ${ }^{2}$. Although similar developments, regulations and the problems connected to them exists in all over the world, I will focus my analysis on the European situation with which I am most familiar.

Within the European Community all public sector tenders have to comply with either the rules in directives 2004/17 or 2004/18 of the European Parliament and the Council. The ultimate goal of these directives is to achieve a transparent, non-discriminatory competition procedure, by giving all interested parties the possibility to submit an offer, and by judging the offers on transparent and objective criteria.

From time to time these tenders led to disputes, some of which ended in legal procedures between the procuring government agency and one of the interested parties. The subsequent court rulings show a legalistic view on the procurement procedures; both the legislation covering the procedures and the requests for quotes are to be read by the letter and taken as literally as possible to ensure equal procedures in all member states. ${ }^{3}$ This interpretation of the rules leaves government bodies in a peculiar state; they have to adhere to strict procedural rules and requirements, while acquiring goods and services in very diverse and often complex settings.

\footnotetext{
${ }^{1}$ http://ec.europa.eu/internal_market/publicprocurement/index_en.htm

this was before the new, stronger requirements were installed. Website visited July 262010

${ }^{2}$ For the current thresholds see COMMISSION REGULATION (EC) No 1177/2009, http://eurlex.europa.eu/LexUriServ/LexUriServ.do?uri=OJ:L:2009:314:0064:0065:EN:PDF, website visited July 29 2010,

${ }^{3}$ In one particularly sad case the government agency complained that the contract was incompletely fullfilled, since no communication devices were installed on the new sewer pumps, while the contract stipulated that the pumps should be able to communicate. The contractor replied by claiming that the pumps were technically capable of communication, but the contract did not stipulate that they actually communicate. The contractor won.
} 
A problem acquiring agencies encounter is that quantities are not known or can not be specified ex ante. For instance, in a road service contract no-one can tell how many holes will be repaired next year, so it is impossible to tell how much work will be granted. It is therefore common practice to negotiate unit-price-contracts and calculate the final bill based on those prices. This way contracts can still be signed ex ante. To compare the offers made for these contracts the acquiring agency requests unit prices from possible suppliers for all products and services that can fall under the contract. These lists of prices are then compared by creating a score rule and selecting the offer with the lowest score. Returning to the road-maintenance example, the list of prices would specify the price for anything from moving the asphalt machine, to the price of a square meter of asphalt, to the costs of replacing side-curbs and road markings. In these cases the score rule is usually known as a fictional work because it simulates a large scale project, including an amount of machine movements, top-layers to be removed and replaced etc. The total cost of this fictional work is calculated for each bidder and the cheapest contractor for the fictional work (lowest score) wins the auction.

At the end of the contract year the final bill is determined by multiplying tendered unitprices with the work done, ignoring the fictional work used for selection. The differences between the quantities in the fictional work and the actual quantities give rise to some unwanted effects and remarkable price quotes. In a tender process that was brought to my attention, one bidder quoted a one time $€ 200,000$ rebate on the total contract, while requiring a mark-up of 100 times the estimated market price for one of the items in the price list. ${ }^{4}$ The random nature of the quantities in the contract will always lead to some price uncertainty on the final bill, but this uncertainty is increased dramatically by such extreme per-unit prices. This extra risk is socially undesirable, even more so for a budget driven organization. In practice there is also the problem that contractors seem to be able to find the misestimates in the score rule better than the government-employees, allowing them to drive up the final bill. This was clearly illustrated in the tender process mentioned above. When the quantities of the fictional work were replaced by the realized quantities from the year before, it became clear that the winning bid would have been the most expensive contractor the year before.

\footnotetext{
${ }^{4}$ Based on price estimations made by the involved government body.
} 
Although this outcome might have been extreme, this type of bidding behavior is fairly common for unit price auctions and is known as skewed or unbalanced bidding. In this paper I add to the literature by proposing two relatively simple remedies to bid skewing that remove the incentive to skew ex ante, an approach that has not been done before. By either hiding the score rule or by awarding the contract to several winners and adding posttender competition the incentive to skew the bids is removed. For the acquiring agency this implies that the procedure can be made to lead to the desired outcomes: fair and non-skewed prices from a market-wide competition in a nondiscriminatory and transparent procedure. Furthermore, I relate these adjustments to the prevailing legal environment.

The remainder of the paper is organized as follows: Section 2 introduces the problem through the economic theory and continues by discussing some solutions found in practice or in the literature. Section 3 goes in to detail by describing both the problem and my solutions in terms of a model and is followed by a simplified example and some concluding remarks. Most of the mathematical results are derived in the appendix.

\section{Related literature}

The theoretical discussion of unbalanced bidding can be split into two strands of literature according to whether they study the problem from the side of the bidders or the side of the bid-takers. The fact that prices in a unit price or scale auction could be set strategically to increase revenue was noticed first in the sector of operations research and construction management. A seminal paper in this aspect is Stark (1974) In this paper Stark shows that one can turn the process of determining the individual prices into a linear programming problem and than solve it. In his paper he takes account of a large amount of problems and possible objectives of the bidders, including practical issues as cashflow requirements etc.

Following Stark quite some papers have been published in the operational research and construction management literature focussing on the issue of how to place the optimal bid, an interesting overview of this literature is given in Cattel et all. (2007). 


\subsection{The theory and empirics of unbalanced bidding from the bid- takers point of view}

Fairly recently a strand of literature, including this paper, has emerged that focuses on the effects of this strategic bidding behavior for the bid-taker. From the bid-takers perspective, the problem of unbalanced bidding can be placed in the larger problem of how to design a multidimensional auction. In this paper, however, I do not propose an optimal mechanism and will abstract from quality considerations. I concede that this potentially limits the scope of application, but think that this is a necessary simplification.

Four arguments can be made to defend this abstraction. First, many governmental organizations (which are my main focus) work with fixed quality standards, such that quality is not part of the procedure. Second, theoretical analysis in Asker \& Cantillon (2008) show that by using a efficient auction fairly good results can be obtained. Thirdly, if different qualities of a certain good/service are possible or needed, they can be added as different goods in the contract, still allowing the bid-taker to weight in quality to some extend. Lastly Onderstal \& Van de Meerendonk (2008) report on experimental results that indicate, that price only auctions can do fairly well as compared to beauty contest. Reassuring me that the limitations are not too damaging. For the rest of the paper I will therefore focus on the problem of unbalanced bidding as a pricing issue.

A seminal paper in this strand of literature is Athey \& Levin (2001, further A\&L). A\&L model the situation of the US Forestry Service auctioning the right to harvest all trees on a tract of land. The Forestry Service surveys the tract to get an estimate of the amount of trees and the relative quantities of the different species. It posts this information toward the interested lumber companies. The lumber companies survey the area as well and create their own estimates that generally differs from the one posted by the forestry service. The lumber companies subsequently send an offer to the Forestry Service specifying the price they are willing to pay per unit of timber for each species. The Forestry Service multiplies the per unit prices of the offers with the quantities they estimated and publicized to select the bidder from which they expect to get the biggest payment for the entire tract. A\&L first solve for the optimal bidding strategy of the bidders, and then use this solution for structural 
analysis. They focus on the two most common types of trees. Their analysis shows that if a bidder has a different estimation of the relative quantities of trees than the Forestry Service, this bidder can increase his profit by increasing the price of the type the Forestry Service relatively overestimated and decrease the price of the other type. They subsequently find evidence that the lumber companies use this strategy in the data. Furthermore their analysis of the data shows that bigger misestimations of the Forestry Service make it more likely that bidders pick up on the misestimation and skew their bid in the correct (profitable) direction. Furthermore bidders appear to use private information. The winning bidder is often the one that skews most, although it is not significantly different in skewness from the runner-up. The average payment per 1000 board feet of timber falls about $3 \%$ short of the payment that was expected from the score of the winning bid. This does not directly translate to revenue loss however, since skewing allows bidders to bid more competitively. Although an increase in the misestimation is correlated with an increase in the skewness of the bids, there is also evidence that the informational rent is competed away, only a non-significant increase in revenue remains for the winning bidder as a result of increased misestimation on the margin.

A further theoretical contribution was by Ewerhart \& Fieseler (2003, henceforth E\&F). They use a reverse auction setting in which a project has to be completed using a fixed amount of material and an amount of labor that depends on the efficiency of the contractor selected. The procurer knows the amount of material needed but only has an estimation of the amount of labor needed. First the procurer posts a price request toward interested contractors. The contractors bid through a unit price for labor and material. These unit prices are then multiplied with their relative weights in the estimate of the acquirer and added to create the final bid. The bidder with the lowest bid is selected. E\&F show that, the bidfunctions (of the final bids) are non-monotonic in the efficiency parameter. Furthermore they show that the acquirer underestimates the payment required, i.e. the true payment is higher than the winning aggregated bid. They go on to show that the acquirer can use the score-rule to intensify competition in such a way that it more than compensates for possible efficiency losses or information rents, which will be discussed in more detail in the solutions subsection below.

A critical empirical analyses was provided by Bajari, Houghton, \& Tadelis(2006). They 
use panel data collected from the California Department of Transportation to estimate the effects of adaptation cost, private information and local market power on the final bill, while also taking incentives to skew into account. Their data analyses suggests that adaptation cost are the most important cost determining factor in the procedures they studied, but they still find a modest but significant mark-up due to skewed bidding, even in the presence of large adaptation costs.

Finally Agarwal, Athey \& Yang (2009) found that the problems in the Pay Per Action auction Google introduced for its ad-words in 2007(the biggest real-time auction in the world) are also quite easily classified as skewed bidding. In this auction the difference between the estimates of Google and the bidders were not only caused by differences in information, but also because the bidders could actively increase or decrease the prevalence of certain actions. A bidder could, for instance, set a high fee for every time a certain link is clicked and then hide or remove the link so that link is always overweighed by Google. By alternating links to be overweighted and underweighted, the system was quite easily played. These issues caused Google to return to the Pay Per Click auction they used before.

\section{2 solutions in theory and practice}

Both in the literature and in practice attempts have been made to solve the problem of skewed bidding, but most of these are based on dealing with the skewed bid ex post, instead of stopping them ex ante. One could argue that the multi-round or hybrid (optimal) mechanism prescribed for the multi-attribute procurement in papers like Che (1993) could be adapted, but this fundamentally changes the mechanism. In this paper I like to add to the literature by suggesting ways to make skewing unprofitable ex ante, without changing the fundamental mechanism of the unit price auction.

The problem of bid skewing has evidently been recognized in both the US and Europe, since the rules governing public procurement allow government agencies to reject "materially unbalanced" (US) or "abnormally low" (EU) bids ${ }^{5}$. Although this regulation might allow

\footnotetext{
${ }^{5}$ US: art. 14.404-2 jo. 15.404-1 Federal Acquisition Regulations.

EU: art 57 DIRECTIVE 2004/17/EC or art 55 DIRECTIVE 2004/18/EC
} 
agencies to reject unbalanced bids, it is does not stop unbalancing. It is only possible to reject an offer once it has been made, implying that these rules are not meant to end skewing, just to deal with it ex post. Furthermore, the rationale for picking the lowest price is to minimize cost, so rejecting the winning bid is, on the face of it, counterproductive. There might be some positive incentive working through these rules, however, since bidding just to get rejected can not be an equilibrium strategy. Unfortunately, for the EU at least this incentive is severely limited through the legal difficulties of defining abnormally low bid. Bajari, Houghton \& Tadelis (2006) do report some anecdotal evidence that this possibility has decreased unbalanced bidding. Skewed bidding is arguably one of the most important reasons to reject bids, which they report happens with $4 \%$ of the bids in the US. This risk of rejection is mentioned within the construction management literature as well, see for instance Cattell et all (2007), so the rules probably have effect. It is important, however, to distinguish between the EU and the US. The US has quite extensive rules on how to deal with irregular bids in the Federal Acquisition Regulation, the EU does not. There have been cases within the EU involving a government agency that rejects an abnormally low offer, but if brought before a court these have granted injunctions quite easily, making it economically less appealing to do so. ${ }^{6}$

Another solution used by many government agencies is to include in their standard terms a clause about severe misestimations. If an estimated quantity is overrun by a certain percentage (usually ranging between 10 and 25\%) the unit price is renegotiated. This has the potential to limit the profits of skewing, although the other party is always at the negotiation table with them.

Many government agencies have tried to reduce the problems by bringing more expertise into the acquiring agency and reducing the gap between the score rule and the expected quantities. This does seem to alleviate the problem, but does not necessarily solve the problem, since estimation always has some error. ${ }^{7}$

\footnotetext{
${ }^{6}$ see for instance: Rb. Arnhem 15 Februari 2010, LJN: BL5214, case number 194578.

A unit price of 0.01 euro's for service on different locations was not enough to conclude that the tender was abnormally low.

${ }^{7} \mathrm{I}$ talked to the people in charge of these procedures in the city of Rotterdam about bid-skewing and
} 
Returning to the papers mentioned before, A\&L note that the Forestry Service can set reserve prices, requiring bidders to bid at least some minimum price for the major species. This effectively limits the room bidders have to skew. Unfortunately, this only works if the bid-taker has enough information on the market prices, because setting these limits too stringently they could scare away bidders, hindering competition. Minimum prices do not however decrease the incentive to skew. In fact it creates a situations in which types are not revealed in the bids since pooling on the reserve prices can and does occur both in theoretical equilibrium and in real outcomes.

Using a mechanism design approach E\&F create an optimal score rule, which can also be seen as a solution. In short, the score rule is used to subsidize inefficient producers, which leads to more competitive pressure on the efficient bidders, and thus lower prices. There are several objections to this solution. First, it requires the acquiring agency to have enough knowledge about the cost structure in the market, which it might not have. In E\&F information is single dimensional, while it is very much multidimensional in real life. When an agency needs more than 500 unit-prices, finding the right score rule for the job maybe very hard or impossible, even if the distribution of cost-types is known. Second, the authors already note that this procedure does not guarantee allocative efficiency. In his efforts to increase competition the acquiring agency creates a positive probability that an inefficient contractor wins. The size of this problem in a one shot game is debatable. In terms of ex ante expected cost, the increased competition more than compensates for the increased cost in case an inefficient contractor wins. The third objection seems most severe, even if we disregard allocative efficiency and assume that the government can determine the optimal score rule, how will the contractors respond in the medium to long run? The optimization in $\mathrm{E} \& \mathrm{~F}$ is static, while many real life procurement situations are repeated over and over again, and thus require a dynamic approach. In the road maintenance example the argument can be made more concrete. Given that contractors are willing to skew to the extent they have shown in the past, what is stopping them from faking inefficiency to profit from this subsidization of inefficiency? In fact, if inefficiency is indirectly rewarded by a chance to win, their reaction was illustrative. They had noticed that basing the score rule on past quantities decreased the amount of skewing, but did not make it disappear. 
why not specialize, or invest in inefficient production technology to optimally exploit this subsidy?

\section{The model}

\section{1 current process, or the rules of the game}

Assume there is one acquiring agency that holds a procurement auction for a contract and there are $N \geq 2$ interested parties, or bidders. At the moment the auction is held the $M$ quantities required to service the contract, summarized in vector $\mathbf{q}$ (vectors are in boldface), are uncertain. Both the agency and all bidders receive a private signal about the quantities, $\mathbf{s}_{i}$, (through out the paper subscripts denote players and superscripts units or

bundles of units, the subscript 0 will be used to denote the agency) that they use to determine their expectations. Furthermore, before bidders submit their bid the agency announces a score function used to rate the bids. This score function is fully described by the vector $\boldsymbol{\rho}$ containing the weights attached to each of the $M$ products needed in the contract. This score function can be based upon the private information of the agency about the quantities. Subsequently all bidders submit a bid consisting of a vector $\mathbf{p}_{i}$ containing $M$ per-unit prices. The agency then selects the winner by picking the lowest of the scores $B_{i}=\mathbf{p}_{\mathbf{i}}^{\mathbf{T}} \boldsymbol{\rho}$, the winning firm serves the contract, while the loosing firms earn a reservation profit normalized to zero.

Since the winning bidder will serve the contract, and has no influence on q, profit maximization is equivalent to revenue maximization and bidders will be treated as revenue maximizers.

E\&F and A\&L show that, in respectively the Symmetric Independent Private Value and the Common Value setting, from the point of view of each bidder the bid can be split in to two relevant parts: his score $B_{i}$ that determines the chance he wins, and the vector $\mathbf{p}_{i}$ that determines the per-unit prices if he wins. This implies that the optimal bid can be determined in two steps, first determine the optimal skew, that is the optimal structure of $\mathbf{p}_{i}$ (given the signals and final bid), and then calculate the optimal score given this skew (and the signal). This is also the strategy that is prescribed by many of the authors in the 
operational research, see Cattel et all. (2007) for examples.

The same process is at work both in the normal unit price auction and in the reverse auction of the unit price procurement procedure. For my purposes the relatively easy to tract SIPV auction therefore suffices and I will treat both parts of the bidding process separately.

Given the bids, the final payments will depend on the realized quantities q. Since these quantities are not known ex ante, the bidders use their private signal $\widehat{\boldsymbol{s}}_{i}=E\left(\mathbf{q} \mid s_{i}, \boldsymbol{\rho}\right)$ to determine their bids.

\subsection{Problem analysis}

The expected revenue of the winner is $\mathbf{p}_{i}^{T} \widehat{\boldsymbol{s}}_{i}$ while the score is $B_{i}=\mathbf{p}_{i}^{T} \boldsymbol{\rho}$, so there is a discrepancy when $\widehat{\mathbf{s}}_{i} \neq \boldsymbol{\rho}$. As is shown in the literature, bidders should overprice any unit that is relatively underweighted in the score function (relative to their expectations), and subsequently underprice any unit that is overweighted, to keep $B_{i}$ on the desired level, while increasing their expected profit.

To illustrate this, take two units for which $\rho^{m}=\rho^{n}$, but $\widehat{s}_{i}^{m}>\widehat{s}_{i}^{n}$, then $B_{i}$ does not increase if $p_{i}^{m}$ is increased by $\varepsilon>0$ while $p_{i}^{n}$ is decreased by $\varepsilon$, i's expected turn-over however

increases by $\left(\widehat{s}_{i}^{m}-\widehat{s}_{i}^{n}\right) \varepsilon>0$, without changing the cost of the work or affecting the chance of winning.

A\&L show that, if one assumes risk aversion of the bidders, the problem can be stated in the following way. Let $\mathbf{z}_{i}$ be the vector of prices that yields the bidders the same (normal) profit-margin on all units. Then define $\Delta \mathbf{p}_{i}=\mathbf{p}_{i}-\mathbf{z}_{i}$ as the offset from this normal vector. $\left\|\Delta \mathbf{p}_{i}\right\|$ Is then a measure of the skewness of the bid. While the extra price variance due to skewing becomes $\operatorname{var}\left(\boldsymbol{\Delta} \mathbf{p}_{i}^{T} \mathbf{q}\right)=\Delta \mathbf{p}_{i}^{T} \sum^{q} \boldsymbol{\Delta} \mathbf{p}_{i}$, with $\sum^{q}$ the covariance matrix of q. This implies that the variance of skewing profits increases quadratically in the skew, while the skewing profit itself only increases linearly. Therefore the possibility frontier linking skewing variance and skewing profits is concave and under risk aversion this problem has a unique solution as in standard portfolio theory.

In the end, for the agency conducting the unit price auction, skewing has the possibility to lead to a higher final bill (due to an information rent) and always leads to larger ex ante price uncertainty, since the variance of the final bill increases quadratically in the amount of 
skewing. For the bidders the procedure has some informational rents, but they come at the cost of unproductive extra risk, which could be hard to bear for the smaller participants in the market.

Both the possible higher final bill and the uncertainty over the final bill are caused by the skewness of the bids. Bidders skew their bids for two reasons. First, it gives them a higher expected profit if they win. Second, it allows them to bid more aggressively and thus increases their chance of winning, which in theory means the winner always skews his bid $(\mathrm{A} \& \mathrm{~L})$. The profitability of skewing is caused by differences between the relative quantities in the score rule $\boldsymbol{\rho}$, and the expected quantities $\widehat{\mathbf{s}}_{i}$. The obvious solution to this problem is decreasing these differences. To achieve this bidders should not posses any information advantage over the acquirer, while in the standard procedure the acquiring agency announces his score rule. By using a score rule equal to or based on his estimate of the real quantities, the agency reveals his estimate. Which means bidders always have at least as much information as the acquirer to base their estimate on. So, although well estimated score rules may reduce the problem, to overcome the problem altogether a different solution should be sought. Franchising the contract can be done, it however changes the nature of the contract quite considerably so falls outside of the scope of this paper.

\section{3 secret score rule}

Keeping the score rule secret can end skewing. Since bidders do not know how the skewness of their bids will affect their chance of winning, they would have to guess at both the agency's estimate and the true state to determine their bid, which makes skewing extremely risky. This possibility will even disappear if the acquiring agency bases the score rule on an unbiased signal of $\mathbf{q}$, so $\boldsymbol{\rho}$ is an unbiased estimator of $\mathbf{q}$ such as $\mathbf{s}_{0}$. In that case $E(\boldsymbol{\rho})=E(\mathbf{q})$ and no expected overweighting exists.

Unfortunately, at least within the EU, a secret score rule is legally difficult. Art. 55(2) of Directive 2004/17/EC and art. 53(2) of Directive 2004/18/EC read, the "contracting authority shall specify,..., the relative weighting which it gives to each of the criteria chosen 
to determine the most economically advantageous tender" ${ }^{8}$. This does not seem to leave much room for secrecy, but the second paragraph of these articles might provide a loophole.

" Those weightings can be expressed by providing for a range with an appropriate maximum spread."

If the spread of this range is big enough to hide $\boldsymbol{\rho}$, the bidders will still have to guess at the way skewing their bid influences their chance of winning. By using a big enough spread, such that $s_{i}^{m} \in\left[\rho^{m}-\underline{\varepsilon^{m}}, \rho^{m}+\bar{\varepsilon}^{m}\right]$ and using a mixed strategy in determining the ranges around different weights (i.e. $\underline{\varepsilon}^{m} \neq \bar{\varepsilon}^{m}$ and both are random) the agency can obscure his estimate to the point that $E(\boldsymbol{\rho})=E(\mathbf{q})$. The mixed strategy also ensures that bidders cannot backwards engineer the agencies estimates from the score rule. I have found no instances in practice where the weights are presented in a spread, and case-law on the subject of transparency does not seem to provide much room. So it seems like a difficult strategy to follow.

\section{4 split award auction}

Instead of offering the entire contract to one winner, it is possible to simultaneously grant parts of the contract to two or more winners. In the EU this can be done trough a framework contract, which can be used to selected 3 or more suppliers simultaneously. This makes this procedure easy to implement, since it is essentially a version of an existing procedure.

Selecting several winners reduces the tender procedure to a pre-selection tool. The auction selects "preferred suppliers" and when a job occurs (a road deteriorates to the point that replacement is needed) the most economically advantageous of the preferred suppliers gets the job. Jobs are described by a vector $\mathbf{q}^{l}$ specifying the quantities required for this sub-part of the larger contract, such that $\mathbf{q}=\sum_{l=1}^{L} \mathbf{q}^{l}$.

Splitting the contract leads to a kind of post-auction competition, which the bidders will have to take into account when preparing their offers. The possibility of the bid-taker to single-sidedly allocate jobs allows him to punish bidders by assigning them the jobs that are

\footnotetext{
${ }^{8}$ Directive 2004/17/EC: water, energy, transport and postal services sectors

And

Directive 2004/18/EC: public works contracts, public supply contracts and public service contracts Are the main directives in public procurement in the EU
} 
intensive in the units they underpriced.

I claim that this procedure solves the bid skewing problem in the sense that it can assign the contract to the most efficient parties and bid skewing is eliminated, while retaining or reattaining the desired non-discriminant, transparent and open procedure that treats all party equally. I will start by showing the efficiency result and then show that an equilibrium exists in which bidders do not skew. Then a simplified example is given where uniqueness of equilibrium can easily be shown.

\subsection{1 efficiency of the procedure}

Suppose the contract is split up in $P$ parts, so there are $P$ objects for sale and $N>P \geqslant 1$ bidders. Bidders are allowed to win at most one object. Valuations $v_{i}$ are independently and identically distributed over some interval and admit cumulative distribution function $F(\cdot)$. Bidder i assigns a value $\alpha_{1} v_{i}$ to object 1 and $\alpha_{2} v_{i}$ to object 2. All $v_{i}$ are private information, $N, a_{p}, \forall p \in[1,2, . ., P]$ and $F(\cdot)$ are common knowledge and identical across bidders, with $\alpha_{P+1}=0$. Without loss of generality I assume $\alpha_{p} \geqslant \alpha_{p+1}$, which means contract parts are ordered in size. The scaling through $\alpha_{p}$ implies that each bidder prefers the first object over the second. The simplest interpretation is to assume bidders prefer a bigger part to a smaller part, which is a natural conclusion if no skewing exists.

All bidders simultaneously submit a private bid $b_{i}$. The acquiring agency ranks the bids in size and the bidder with the highest bid receives object 1 and pays $\alpha_{1} b_{i}$, the runner up gets object 2 and pays $\alpha_{2} b_{i}$ etc. Note that payment also varies with the contract size, i.e. the payment is also scaled trough the series $\alpha$.

Proposition 1 In a procedure with several winners an equilibrium with an efficient allocation still exists.

Allocative efficiency requires the $P$ objects to go to the $P$ bidders with the highest valuations in order of their valuation. This requires bidders to follow a bidding strategy that is symmetric and monotonically increasing in $v_{i}$ so I will focus on those strategies $\beta\left(v_{i}\right)$ that posses these qualities and have an inverse function $\beta^{-1}(b)=\sigma(b)=v$. 
Denoting with $u[\cdot]$ a concave utility function that is the same for all bidders, and defining:

$$
\left.\left.\Upsilon(x)=C_{n-1}^{p-1}[(1-F(x)))^{p-1}(F(x))\right)^{n-p}\right]
$$

the game has an equilibrium in bidfunctions where all bidders use the following bidfunction (derivation in appendix)

$$
\beta\left(v_{i}\right)=\int_{0}^{v_{i}}\left(\frac{\sum_{p=1}^{P} \alpha_{p} u\left[(x-b) \alpha_{p}\right] \Upsilon^{\prime}(\sigma(b))}{\sum_{p=1}^{P} \alpha_{p}^{2} u^{\prime}\left[(x-b) \alpha_{p}\right] \Upsilon(\sigma(b))}\right) d x
$$

Which is monotonically increasing in $v_{i}$ if $\alpha_{p} u^{\prime}\left[\left(v_{i}-b\right) \alpha_{p}\right] \geqslant \alpha_{p+1} u^{\prime}\left[\left(v_{i}-b\right) \alpha_{p+1}\right]$. This condition holds trivially if $\alpha_{1}=1$ and if $\alpha_{p}=\alpha_{p+1}$, so the constraint is not very restrictive. As long as the contract sizes are chosen reasonably and ordered in size as assumed the bid functions are increasing.

For risk neutral bidders the bid function can be determined exactly:

$$
\beta\left(v_{i}\right)=v_{i}-\frac{\int_{0}^{v_{i}} \sum_{p=1}^{P} \alpha_{p} C_{n-1}^{p-1}\left[(1-F(x))^{p-1}(F(x))^{n-p}\right] d x}{\sum_{p=1}^{P} \alpha_{p} C_{n-1}^{p-1}\left[\left(1-F\left(v_{i}\right)\right)^{p-1}\left(F\left(v_{i}\right)\right)^{n-p}\right]}
$$

Which is monotonically increasing in $\mathrm{v}$ if $\alpha_{p} \geqslant \alpha_{p+1}$ (see appendix) which holds trivially if the contracts are ordered in size and is the same condition as before since under risk neutrality the first derivative to $u$ is constant. This bid function strongly resembles the bidfunctions in the single object first price sealed bid auction, in fact using $P=1$ and $\alpha_{1}=1$ yields the standard bid-function.

\subsubsection{Balancing the bids}

To see that skewing is unprofitable in this situation let the contract be split up into two parts, $P=2$, such that every time a job occurs, the acquiring agency can select one of the two preferred suppliers, i and $\mathrm{j}$. Each job can be described with a vector, $\mathbf{q}^{l}$, containing all quantities needed to complete the job. The price for each job is $P_{i}^{l}=\mathbf{p}_{i}^{T} \mathbf{q}^{l}$.

Proposition 2 Conditional on the procedure being allocatively efficient, the post-tender competition will make skewing unprofitable and thus end bid skewing. 
After the preferred suppliers are selected, the agency assigns each job using a "minitender", he calculates $P_{i}^{l}$ and $P_{j}^{l}$ and selects the lowest one, given the prices offered in the original tender. The expected skewing profit of a job to the bidder that gets this job is: $E\left(\Delta \mathbf{p}_{i}^{T} \mathbf{q}^{l} \mid P_{i}^{l}<P_{j}^{l}\right)$, which can be both positive and negative, depending on the skew of his fellow preferred supplier.

There are four possibilities after the auction for which interim expected skewing-profits can be determined:

1. the preferred suppliers have both not skewed;

2. only one of them skewed, the other did not skew;

3. they have skewed in different directions;

4. they have skewed in the same directions.

Since there is no problem in case 1, I will not treat it in debt.

Proposition 1 establishes allocative efficiency of the procedure, so I will assume that the two preferred supplier, $\mathrm{i}$ and $\mathrm{j}$, are the most efficient parties, and thus $\mathbf{z}_{i} \approx \mathbf{z}_{j}$.

ad 2. If only $i$ skewed, and $j$ bids $\mathbf{z}_{j}$ it is quite easy to see that

$P_{i}^{l}<P_{j}^{l} \rightarrow\left(\mathbf{p}_{i}-\mathbf{z}_{i}\right)^{T} \mathbf{q}^{l} \lesssim\left(\mathbf{p}_{j}-\mathbf{z}_{j}\right)^{T} \mathbf{q} \rightarrow \boldsymbol{\Delta} \mathbf{p}_{i}^{T} \mathbf{q}^{l} \lesssim \mathbf{0} \mathbf{q}^{l}$ such that $E\left(\sum_{1}^{L} \boldsymbol{\Delta}_{\mathbf{p}_{i}^{T}}^{T} \mathbf{q}^{l} \mid P_{i}^{l}<\right.$ $\left.P_{j}^{l}\right)<0$ as long as $\mathbf{z}_{i} \approx \mathbf{z}_{j}$. This is intuitive since prices for this job are on average below the zero skewing-profit prices of the next competitor.

ad 3 If they skewed on different units altogether, they both get all the jobs they underpriced and thus have a negative skewing profit. To see this, realize that to keep their score $B_{i}=\mathbf{p}_{i}^{T} \boldsymbol{\rho}$ at a winning level they have to skew as much downward as upward (weighted through the score rule). Since they skewed in different directions, the acquiring agency can assign them all jobs they underpriced. The jobs they overpriced go to the other player (who might have underpriced those) at least partially. This means skewing decreases profit as long as those overpriced units they incidentally get, do not compensate for taking the full loss over the underpriced units. Therefore the expected value is negative as long as the score 
rule is close enough to the expected quantities and I will assume $E\left(\Delta \mathbf{p}_{i}^{T} \mathbf{q}^{l} \mid P_{i}^{l}<P_{j}^{l}\right)<0$ as well.

ad 4 If both skewed on the same units and in the same way two situations are possible: If $\Delta \mathbf{p}_{i}^{T} \mathbf{q}^{l}, \Delta \mathbf{p}_{j}^{T} \mathbf{q}^{l}<0$, the skewing-profit is negative and decreases linearly in the amount of skewing, so the one that skews most would have most losses. However given

$\mathbf{z}_{i} \approx \mathbf{z}_{j},\left\|\boldsymbol{\Delta} \mathbf{p}_{i}\right\|>\left\|\boldsymbol{\Delta} \mathbf{p}_{j}\right\| \rightarrow\left(\Delta \mathbf{p}_{i}+\mathbf{z}_{i}\right)^{T} \mathbf{q}^{l} \lesssim\left(\Delta \mathbf{p}_{j}+\mathbf{z}_{j}\right)^{T} \mathbf{q}^{l} \rightarrow P_{i}^{l} \lesssim P_{j}^{l}$, so that the one that skews most is most likely to get the jobs intensive in the products he underpriced, therefore $E\left(\Delta \mathbf{p}_{i}^{T} \mathbf{q}^{l} \mid P_{i}^{l}<P_{j}^{l} ; \Delta \mathbf{p}_{i}^{T} \mathbf{q}^{l}, \Delta \mathbf{p}_{j}^{T} \mathbf{q}^{l}<0\right)<0$.

If $\Delta \mathbf{p}_{i}^{T} \mathbf{q}^{l}, \boldsymbol{\Delta} \mathbf{p}_{j}^{T} \mathbf{q}^{l}>0$ the reverse holds. The skewing-profit increases linearly in the amount of skewing, but

$$
\mathbf{z}_{i} \approx \mathbf{z}_{j},\left\|\boldsymbol{\Delta} \mathbf{p}_{i}\right\|<\left\|\boldsymbol{\Delta} \mathbf{p}_{j}\right\| \rightsquigarrow\left(\Delta \mathbf{p}_{i}+\mathbf{z}_{i}\right)^{T} \mathbf{q}^{l} \lesssim\left(\Delta \mathbf{p}_{j}+\mathbf{z}_{j}\right)^{T} \mathbf{q}^{l} \rightarrow P_{i}^{l} \lesssim P_{j}^{l} \text {. So the one with }
$$
the smallest skew is most likely to get the job. In this case skewing-profits can be positive but only for the one with the smallest skew.

By combining the last two situations one can conclude the expected skewing-profit is negative in situation 4 as well. To keep their score on a winning level, the (score rule weighted) average positive skew should be of similar size to the average downward skew within each bid. Then, as long as the score rule is close enough to the real outcomes, bidders either get a relatively big loss or a relatively small profit of skewing. So as long as the score rule is close enough to the expected quantities, the interim expected value of a skew is negative.

The ex ante expected skewing-profit, $E\left(\Delta \mathbf{p}_{i}^{T} \mathbf{q}^{l} \mid P_{i}^{l}<P_{j}^{l}\right)$ is a convex combination of the expected profit in the four possible situations. If a score rule is chosen that is close to the actual quantities, the interim expected skewing-profit is non positive in all situations and strictly negative in at least one, making skewing unprofitable in expected terms. Therefore, skewing should disappear if a score rule is used that is close enough to the real quantities. Using a score rule that is equal to the expected values thus has a double purpose, it selects the sellers that are most efficient and helps prevent skewing. 


\subsection{3 conclusion}

Proposition 1 shows that in equilibrium the procedure is efficient if the valuations are symmetric, private and independently distributed. Proposition 2 shows that in equilibrium the bidders will not want to skew given that the procedure is efficient and the others bidders don't skew. If bidders don't skew, their valuation of the contract only depends on their type $\mathbf{z}_{i}$, which is private and can be assumed to be independent. So this procedure has an equilibrium in which bidders do not skew their bids and the allocation is efficient.

\section{Illustration of the split-award auction}

\section{1 balancing the bid, binomial case}

To make the statements in the last section more tangible some simplifications are in order. Assume again that a reverse auction has been used to select two preferred suppliers, $P=2$, but focus for now on only 2 elements of the vector $\mathbf{q}$, product $a$ and product $b$ with $\rho^{a}=$ $\rho^{b}=\rho$. Whether or not a unit of these products is required in each job is independently and binomially distributed (either 1 or 0 units are needed). The chance a unit of $a(b)$ is needed is $\pi^{a}\left(\pi^{b}\right)$. The bidders quantity estimation then becomes their estimation of this probability and satisfies $\left\{s_{i}^{a}, s_{i}^{b}\right\}=\left\{s_{j}^{a}, s_{j}^{b}\right\}=\left\{s^{a}, s^{b}\right\}$, furthermore both elements cost $c$ to produce. The expected profit for a bidder getting the entire contract then becomes:

$$
\Pi_{\text {full }}=s^{a}\left(1-s^{b}\right)\left(p_{i}^{a}-c\right)+s^{b}\left(1-s^{a}\right)\left(p_{i}^{b}-c\right)+s^{b} s^{a}\left(p_{i}^{b}-c+p_{i}^{a}-c\right)
$$

Then increasing the price of $a$ with $\Delta p$ while decreasing the price of $b$ with the same amount creates expected skewing profit per job:

$$
\Pi^{\text {skew }}=\Delta p\left[s^{a}\left(1-s^{b}\right)-s^{b}\left(1-s^{a}\right)\right]
$$

While their score is

$$
B_{i}=\rho\left(p_{i}^{a}+p_{i}^{b}\right)
$$

So, if the contract is awarded in one piece, it is profitable to skew if $\left\{s_{i}^{a}, s_{i}^{b}\right\} \neq\left\{\rho^{a}, \rho^{b}\right\}$ and bidders set $\Delta p$ positive (negative) if $s^{a}>s^{b}\left(s^{a}<s^{b}\right)$, i.e. if $a$ is underweighted the 
price of $a$ is increased. Note that the price of $b$ is decreased to maintain the level of the final bid $B_{i}$, just like before.

The split-award procedure is as before, the agency assigns the jobs to the preferred suppliers based on their price for that individual job.

Proposition 3 In the binomial case the unique equilibrium is a pure strategy equilibrium where no player skews

After winners are selected, nature can draw 4 types of jobs: jobs that only require $a$; jobs that only require $b$; jobs that require both $a$ and $b$; and jobs that require no units of $a$ or $b$. In the last two cases the skew on units $a$ and $b$ has no influence on the price of the job and the skewing profit is 0 per definition, so these can be ignored.

Focussing on the first two situations it is clear that positively skewing in $a$, will lead to a problem if $b$ is required and vice versa. The pure strategy equilibrium is therefore quite easily constructed, if bidder $i$ does not skew, the best response of bidder $j$ is not to skew as well. Without skewing the situation is essentially Bertrand competition, so the only thing one has to realize is that by increasing the price of $a$ bidder $j$ ensures he is more expensive in $a$ and therefore never gets any of the profitable jobs. However, if a job comes up requiring $b$ he has the lowest price, gets the job and takes the loss, making skewing unprofitable.

No equilibrium in mixed strategies exists. A mixed equilibrium where player i skews a fixed and known amount with some probability does not exist. The best response of player $\mathrm{j}$ to such a strategy of $\mathrm{i}$ is to skew slightly less and get only the profitable jobs, i's best response is then to undercut j's best response etc. Since there is no restriction on the biddingspace this logic also excludes strategies over a noncontinuous interval, which is like Bertrand competition in skewness instead of in prices.

As in Bertrand competition it is theoretically possible to have a mixed strategy equilibrium where bidders skew with some distribution over some interval. To show that these strategies can not be equilibrium either, assume first that an equilibrium exists where both $i$ and $j$ skew over some appropriate interval $[c, d]$. Assume $s^{a}>s^{b}$ so $\Delta p \geq 0$ and define $F(\cdot)$ as the Cumulative Distribution Function of $\Delta p$. In that case we know that the expected 
profit of skewing for each single job of a winning bidder is the same on the entire interval:

$$
\Pi^{\text {skew }}=s^{a}(1-F(\Delta p)) \Delta p-s^{b} F(\Delta p) \Delta p=\bar{e}
$$

rewriting, taking into account that $\bar{e}$ must be fixed in equilibrium, this leads to:

$$
F(\Delta p)=\frac{s^{a}-\bar{e} / \Delta p}{s^{a}+s^{b}}
$$

Since $F(\cdot)$ is a CDF it should be weakly increasing over some interval until it reaches $1 . F(\cdot)$ can only ever be 1 if $\bar{e} / \Delta p=-s^{b}$, while to derive this function we assumed $\Delta p \geq 0$ such that $\bar{e} / \Delta p=-s^{b}$ implies $\bar{e}<0$. Since any player can simply guarantee himself a zero skewing profit by not skewing, playing a strategy with negative expected value is strictly dominated by not skewing.

The same reasoning used to exclude mixed equilibria with fixed and known amounts of skewness can be used to exclude mass-points in the distribution everywhere except on the lower bound. However, if a distribution has a mass-point only on the lower bound it is still

continuous and weakly increasing over the interval. Under the assumption $\bar{e}>0$ and $\Delta p>0$ the first derivative of the CDF is negative, which is also not possible, so we can exclude these equilibria as well.

Since this is all known ex-ante, so long as $s^{b}, s^{a} \neq 0$ the unique equilibrium of this game is one where no player skews.

\section{Conclusions and concluding remarks}

Although bid skewing is a common problem in unit price auctions, solutions do exist. In this paper I showed two relatively easy adjustments to the unit price auction that could decrease if not eliminate bid skewing altogether. Even though the first solution, obscuring the score rule, might not be legally allowed for governmental agencies (within the EU at least), they to have a readily available solution in the split award procedure in a framework contract. The non-governmental parties using a reverse auction are off course not bound by the transparency requirements.

If the split award procedure is chosen, the way the contract is split has profound influence on the way bidders should behave. The exact effects are not analyzed in this paper, but a 
related subject is already analyzed in Alcalde \& Dahm (2009). They show that strategically choosing the contracts sizes might be used to mitigate the loss in efficiency caused by selecting more than only the most efficient bidder.

A problem I have ignored in this paper sofar is collusion. In splitting the contract, the procedure can become very sensitive to collusion, see for instance Anton \& Yao (1989). The procedure I propose is more robust then the one described there, because the decision to split is taken exogenously. This makes it impossible for bidders to select price-quantity combinations. In Anton \& Yao (1989) it is this ability, just as in second degree price discrimination, that helps bidders coordinate. Having said that, the possibilities of a bid ring to dissipate profits increases if more winners are selected, making bidding rings easier to set up. On the other hand, if the ring skews, this makes it profitable for any bidder to break the ring by skewing slightly less, which automatically gives the tenderer the possibility to punish the skewing preferred supplier. How this plays out in theory or in practice remains for further research.

\section{References}

1. Alcalde \& Dahm, (2009), "Bidding for Being a Seller", Unpublished

2. Anton \& Yao, (1989), "Split Awards, Procurement, and Innovation.", RAND Journal of Economics, Vol. 20, No. 4 , pp. 538-552

3. Ashworth \& Bueno de Mesquita (2006), "Monotone Comparative Statics for Models of Politics", American Journal of Political Science, Vol. 50, No. 1 pp. 214-231

4. Athey \& Levin (2001). "Information and Competition in U.S. Forest Service Timber Auctions," Journal of Political Economy, University of Chicago Press, vol. 109(2) pp.375-417

5. Bajari, Houghton, \&Tadelis (2006), "Bidding for Incomplete Contracts," Working Paper Number W12051, National Bureau of Economic Research 
6. Cattel, Bowen \& Kaka (2007), "Review of unbalanced Bidding Models in Contrstruction", Journal of Construction Engineering and Management. pp 562-573

7. Che (1993), "Design Competition Through Multidimensional Auctions." RAND Journal of Economics, Vol.24, pp. 668-680.

8. Clough \& Sears, "Construction Contracting", 5th ed. New York: Wiley, (1986) .

9. Ewerhart \& Fieseler (2003), "Procurement Auctions and Unit-Price Contracts", The RAND Journal of Economics, Vol. 34(3) pp. 569-581

10. Fieseler, (1999) "Three Essays in the Theory of Mechanisms." Ph.D. dissertation, Department of Economics, University of Mannheim, 1999.

11. Harris \& Raviv, (1981), "Allocation Mechanisms and the Design of Auctions", Econometrica, Vol. 49, No. 6 , pp. 1477-1499

12. Hinze, Construction Contracts. New York: McGraw-Hill, (1992).

13. Maskin \& Riley (1989), "Optimal multi-unit auctions", For: the economics of missing markets information and games, Hahn, Clarendon Press, Oxford, 1989, pp 312-335

14. Menezes \& Monteiro (1998), "Simultaneous Pooled Auctions", The Journal of Real Estate Finance and Economics, Springer, vol. 17(3), pages 219-32,

15. Milgrom \& Roberts, (1994), " Comparing Equilibria", The American Economic Review, Vol. 84 no. 3, pp 441-459

16. Milgrom \& Shannon, (1994), "Monotone Comparative Statics." Econometrica vol. 62, pp.1089-1122

17. Missbauer \& Hauber (2006), "Bid calculation for construction projects: Regulations and incentive effects of unit price contracts", European Journal of Operational Research, Vol.171, pp.1005-1019. 
18. Onderstal \& Van de Meerendonk (2008), "How (Not) to Design Procurement Mechanisms: A Laboratory Experiment, in: Best Practices in Public Procurement", Proceedings of the 3rd International Public Procurement Conference, pp.391-421

19. Stark (1974), "Unbalanced Highway Contract Tendering", Operational Research Quarterly, Vol. 25 , pp. $373-388$

20. Agarwal, Athey \& Yang (2009), "Skewed Bidding in Pay-per-Action Auctions for Online Advertising," American Economic Review, vol. 99(2), pp 441-47

21. EDGEWORTH, F. (1925): "The Pure Theory of Monopoly," in Papers Relating to Political Economy, Vol. 1. London: MacMillan, pp. 111-142

\section{7 appendix}

\subsection{Derivation of bid-functions}

Denoting by $Y_{(\cdot)}$ the order statistics, such that $\max \left\{b_{1, \cdots}, b_{n}\right\}=Y_{(n)}$, and having $\sigma(\cdot)=\beta^{-1}$, such that $\sigma(b)=v$, the expected profit of an offer $b_{i}$ is :

$$
\pi_{i}(b)=\operatorname{Pr}\left(b_{i}=Y_{(n)}\right) * \alpha_{1}\left(v_{i}-b\right)+\operatorname{Pr}\left(b_{i}=Y_{(n-1)}\right) \alpha_{2}\left(v_{i}-b\right) \ldots
$$

given symmetry of bidders and strategies: $b_{i}=\beta\left(v_{i}\right)$, so $\sigma(b)=v$ and recalling that $F(\cdot)$ is the CDF of $v$ :

$$
\begin{aligned}
& \pi_{i}\left(b, v_{i}\right)=a_{1}\left(v_{i}-b\right) C_{n-1}^{0}(1-F(\sigma(b)))^{0}(F(\sigma(b)))^{n-1}+a_{2}\left(v_{i}-b\right) C_{n-1}^{0}(1-F(\sigma(b)))^{1}(F(\sigma(b)))^{n-2} . . \\
& \pi_{i}\left(b, v_{i}\right)=\sum_{p=1}^{P}\left(v_{i}-b\right) \alpha_{p} C_{n-1}^{p-1}(1-F(\sigma(b)))^{p-1}(F(\sigma(b)))^{n-p}
\end{aligned}
$$

where $C$ is the binomial coefficient.

Then, adapted from Menezes \& Monteiro (1998), define:

$$
\left.\left.\Psi(x)=\sum_{p=1}^{P} \alpha_{p} C_{n-1}^{p-1}[(1-F(x)))^{p-1}(F(x))\right)^{n-p}\right]
$$


Lemma 1 for any integer $P, 1 \leq P<N$, and $\alpha \in R^{p+1}, a_{p+1}=0^{9}$

$$
\frac{\partial}{\partial x} \Psi(x)=f(x) \sum_{p=1}^{l}\left(a_{p}-a_{p+1}\right)(n-p) C_{n-1}^{p-1}\left((1-F(x))^{p-1}(F(x))^{n-p-1}\right)=\Psi^{\prime}(x)
$$

proof see below. Then the profit function can be written as:

$$
\pi_{i}(b)=\left(v_{i}-b\right) \Psi(\sigma(b))
$$

The FOC becomes:

$$
\frac{\partial \pi_{i}\left(b, v_{i}\right)}{\partial b}=\left(v_{i}-b\right) \sigma^{\prime}(b) \Psi^{\prime}(\sigma(b))-\Psi(\sigma(b))=0
$$

Since I assume the bidding-function to be twice differentiable and symmetric across bidders, I can replace $\sigma^{\prime}(v)$ by $\frac{1}{\beta^{\prime}(v)}, b$ by $\beta\left(v_{i}\right)$ and $\sigma(b)$ by $v_{i}$, then rewriting yields:

$$
v_{i} \Psi^{\prime}\left(v_{i}\right)=\beta^{\prime}\left(v_{i}\right) \Psi\left(v_{i}\right)+\beta\left(v_{i}\right) \Psi^{\prime}\left(v_{i}\right)
$$

Note that $\beta^{\prime}(v) \Psi(v)+\beta(v) \Psi^{\prime}(v)=[\beta(v) \Psi(v)]^{\prime}$, integrating both sides and setting $\beta(0)=0$ yields:

$\beta\left(v_{i}\right)=\frac{\int_{0}^{v_{i}} x \Psi^{\prime}(x) d x}{\Psi\left(v_{i}\right)}=\frac{\int_{0}^{v_{i}} x f(x) \sum_{p=1}^{P}\left(a_{p}-a_{p+1}\right)(n-p) C_{n-1}^{p-1}\left((1-F(x))^{p-1}(F(x))^{n-p-1}\right) d x}{\sum_{p=1}^{P} \alpha_{t} C_{n-1}^{p-1}\left[\left(1-F\left(v_{i}\right)\right)^{p-1}\left(F\left(v_{i}\right)\right)^{n-p}\right]}$

or alternatively, trough integration by parts:

$$
\beta\left(v_{i}\right)=v_{i}-\frac{\int_{0}^{v_{i}} \sum_{p=1}^{P} \alpha_{p} C_{n-1}^{p-1}\left[(1-F(x))^{p-1}(F(x))^{n-p}\right] d x}{\sum_{p=1}^{P} \alpha_{p} C_{n-1}^{p-1}\left[\left(1-F\left(v_{i}\right)\right)^{p-1}\left(F\left(v_{i}\right)\right)^{n-p}\right]}
$$

Which is monotonically increasing in $\mathrm{v}$ if $\alpha_{p}-\alpha_{p+1} \geq 0$ (see below) which holds trivially if the contracts are ordered in size.

Allowing for risk aversion the problem has to be slightly restated. Given symmetry amongst bidders, $\beta(v)=b$, and $\sigma(b)=v$ being used by other players as well so

Assume all bidders have the same utility function $u[\cdot]$, their problem becomes:

$$
\max _{b} U\left(\pi_{i}\left(b, v_{i}\right)\right): \sum_{p=1}^{P} u\left[\left(v_{i}-b\right) \alpha_{p}\right] C_{n-1}^{p-1}(1-F(\sigma(b)))^{p-1}(F(\sigma(b)))^{n-p}
$$

\footnotetext{
${ }^{9}$ addapted from Menezes \& Monteiro(1998)
} 
Then define:

$$
\left.\left.\Upsilon(x)=\alpha_{p} C_{n-1}^{p-1}[(1-F(x)))^{p-1}(F(x))\right)^{n-p}\right]
$$

such that:

$$
U\left(\pi_{i}\left(b, v_{i}\right)\right)=\sum_{p=1}^{P} u\left[\left(v_{i}-b\right) \alpha_{p}\right] \Upsilon(\sigma(b))
$$

Then the FOC becomes:

$$
\begin{aligned}
& \frac{\delta U\left(\pi_{i}\left(b, v_{i}\right)\right)}{\delta b}=\sum_{p=1}^{P} u\left[\left(v_{i}-b\right) \alpha_{p}\right] \Upsilon^{\prime}(\sigma(b)) \sigma^{\prime}(b)-\alpha_{p} u^{\prime}\left[\left(v_{i}-b\right) \alpha_{p}\right] \Upsilon(\sigma(b))=0 \\
& \sum_{p=1}^{P} u\left[\left(v_{i}-b\right) \alpha_{p}\right] \Upsilon^{\prime}(\sigma(b)) \sigma^{\prime}(b)=\sum_{p=1}^{P} \alpha_{p} u^{\prime}\left[\left(v_{i}-b\right) \alpha_{p}\right] \Upsilon(\sigma(b))
\end{aligned}
$$

Since I assume the bidding-function to be twice differentiable, I can replace $\sigma^{\prime}\left(v_{i}\right)$ by $\frac{1}{\beta^{\prime}\left(v_{i}\right)}$,

$$
\sum_{p=1}^{P} u\left[\left(v_{i}-b\right) \alpha_{p}\right] \Upsilon^{\prime}(\sigma(b))=\beta^{\prime}\left(v_{i}\right) \sum_{p=1}^{P} \alpha_{p} u^{\prime}\left[\left(v_{i}-b\right) \alpha_{p}\right] \Upsilon(\sigma(b))
$$

Then rewriting and integrating, while setting $\beta(0)=0$ yields

$$
\beta\left(v_{i}\right)=\int_{0}^{v_{i}}\left(\frac{\sum_{p=1}^{P} \alpha_{p} u\left[(x-b) \alpha_{p}\right] \Upsilon^{\prime}(\sigma(b))}{\sum_{p=1}^{P} \alpha_{p}^{2} u^{\prime}\left[(x-b) \alpha_{p}\right] \Upsilon(\sigma(b))}\right) d x
$$

\section{2 proof of Lemma 3}

Take $\mathrm{N}=5$ and $\mathrm{P}=4$

$$
\begin{aligned}
& \pi=a_{1} C_{4}^{0}(1-F(x))^{0}(F(x))^{4}+a_{2} C_{4}^{1}(1-F(x))^{1}(F(x))^{3}+a_{3} C_{4}^{2}(1-F(x))^{2}(F(x))^{2} \\
& +a_{4} C_{4}^{3}(1-F(x))^{3}(F(x))^{1} \\
& \frac{\partial \pi}{\partial x}=a_{1} 4 C_{4}^{0}(F(x))^{3} f(x)-a_{2} C_{4}^{1}(F(x))^{3} f(x)+a_{2} 3 C_{4}^{1}(1-F(x))^{1}(F(x))^{2} f(x) \\
& -a_{3} 2 C_{4}^{2}(1-F(x))^{1}(F(x))^{2} f(x)+a_{3} 2 C_{4}^{2}(1-F(x))^{2}(F(x))^{1} f(x) \\
& -a_{4} 3 C_{4}^{3}(1-F(x))^{2}(F(x))^{1} f(x)+a_{4} C_{4}^{3}(1-F(x))^{3} f(x)
\end{aligned}
$$

simplifying and generalizing:

$$
\begin{aligned}
& \pi^{\prime}(x)=f(x)\left(\begin{array}{c}
\left(a_{1}-a_{2}\right) 4 C_{4}^{0}(F(x))^{3}+\left(a_{2}-a_{3}\right) 3 C_{4}^{1}(1-F(x))^{1}(F(x))^{2} \\
+\left(a_{3}-a_{4}\right) 2 C_{4}^{2}(1-F(x))^{2}(F(x))+a_{4} 4 C_{4}^{3}(1-F(x))^{3}
\end{array}\right) \\
& \pi^{\prime}(x)=f(x) \sum_{p=1}^{P}\left(a_{p}-a_{p+1}\right)(n-p) C_{n-1}^{p-1}\left((1-F(x))^{p-1}(F(x))^{n-p-1}\right)
\end{aligned}
$$

\subsection{Proof of monotonicity of bid functions under risk neutrality}

$$
\beta\left(v_{i}\right)=v_{i}-\frac{\int_{0}^{v_{i}} \sum_{p=1}^{P} \alpha_{p} C_{n-1}^{p-1}\left[(1-F(x))^{p-1}(F(x))^{n-p}\right] d x}{\sum_{p=1}^{P} \alpha_{p} C_{n-1}^{p-1}\left[(1-F(v))^{p-1}(F(v))^{n-p}\right]}
$$

differentiating according to the rules for fractions and simplifying: 


$$
\begin{aligned}
& \beta^{\prime}\left(v_{i}\right)= 1-\frac{\left[\sum_{p=1}^{P} \alpha_{p} C_{n-1}^{p-1}\left[\left(1-F\left(v_{i}\right)\right)^{p-1}\left(F\left(v_{i}\right)\right)^{n-p}\right]\right] *\left[\sum_{p=1}^{P} \alpha_{p} C_{n-1}^{p-1}\left[\left(1-F\left(v_{i}\right)\right)^{p-1}\left(F\left(v_{i}\right)\right)^{n-p}\right]\right]}{\left[\sum_{p=1}^{P} \alpha_{p} C_{n-1}^{p-1}\left[\left(1-F\left(v_{i}\right)\right)^{p-1}\left(F\left(v_{i}\right)\right)^{n-p}\right]\right]^{2}} \\
& \frac{-\int_{0}^{v_{i}} \sum_{p=1}^{P} \alpha_{p} C_{n-1}^{p-1}\left[(1-F(x))^{p-1}(F(x))^{n-p}\right] d x *\left[\sum_{p=1}^{P} \alpha_{p} C_{n-1}^{p-1}\left[\left(1-F\left(v_{i}\right)\right)^{p-1}\left(F\left(v_{i}\right)\right)^{n-p}\right]\right]^{\prime}}{\left[\sum_{p=1}^{P} \alpha_{p} C_{n-1}^{p-1}\left[\left(1-F\left(v_{i}\right)\right)^{p-1}\left(F\left(v_{i}\right)\right)^{n-p}\right]\right]^{2}} \\
& \beta^{\prime}\left(v_{i}\right)= 1-\left(1-\frac{\int_{0}^{v_{i}} \sum_{p=1}^{P} \alpha_{p} C_{n-1}^{p-1}\left[(1-F(x))^{p-1}(F(x))^{n-p}\right] d x}{\left[\sum_{p=1}^{P} \alpha_{p} C_{n-1}^{p-1}\left[\left(1-F\left(v_{i}\right)\right)^{p-1}\left(F\left(v_{i}\right)\right)^{n-p}\right]\right]^{2}}\right. \\
&\left.*\left[\sum_{p=1}^{P} \alpha_{p} C_{n-1}^{p-1}\left[\left(1-F\left(v_{i}\right)\right)^{p-1}\left(F\left(v_{i}\right)\right)^{n-p}\right]\right]^{\prime}\right) \\
& \beta^{\prime}\left(v_{i}\right)= \frac{\int_{0}^{v_{i}} \sum_{p=1}^{P} \alpha_{p} C_{n-1}^{p-1}\left[(1-F(x))^{p-1}(F(x))^{n-p}\right] d x}{\left[\sum_{p=1}^{P} \alpha_{p} C_{n-1}^{p-1}\left[\left(1-F\left(v_{i}\right)\right)^{p-1}\left(F\left(v_{i}\right)\right)^{n-p}\right]\right]^{2}} \\
& *\left[\sum_{p=1}^{P} \alpha_{p} C_{n-1}^{p-1}\left[\left(1-F\left(v_{i}\right)\right)^{p-1}\left(F\left(v_{i}\right)\right)^{n-p}\right]\right]^{\prime}
\end{aligned}
$$

Where the last inequality holds, because it is the integral of a strictly positive function times a sum of positive terms as long as $a_{p}-a_{p+1} \geq 0$, divided by a square. So for any series $\alpha$ for which $a_{p}-a_{p+1} \geq 0$ holds the function is increasing in $\mathrm{v}$ or in terms of the contracts, the contracts are ordered in terms of size, which can be assumed without loss of generality.

\section{4 monotonicity of the bid functions under risk aversion}

Recall that the bidfunction can be expressed as:

$$
\beta\left(v_{i}\right)=\int_{0}^{v_{i}}\left(\frac{\sum_{p=1}^{P} u\left[(x-b) \alpha_{p}\right] \Upsilon^{\prime}(\sigma(b))}{\sum_{p=1}^{P} \alpha_{p} u^{\prime}\left[(x-b) \alpha_{p}\right] \Upsilon(\sigma(b))}\right) d x
$$

To check that this is indeed an increasing function of $v_{i}$, as assumed, I follow the Monotone Comparative Statics approach from Milgrom \& Shannon (1994) and Milgrom \& Roberts, 
(1994). Returning to the goal function to check for the required single crossing property, we see that in optimum:

$$
\begin{aligned}
& \frac{\partial U\left(\pi_{i}\left(b, v_{i}\right)\right)}{\partial v_{i}}=\sum_{p=1}^{P} \alpha_{p} u^{\prime}\left[\left(v_{i}-b\right) \alpha_{p}\right] \Upsilon(\sigma(b))=0 \\
& \frac{\partial^{2} U\left(\pi_{i}(b, v)\right)}{\partial b \delta v}=\sum_{p=1}^{P}-\alpha_{p}^{2} u^{\prime \prime}\left[\left(v_{i}-b\right) \alpha_{p}\right] \Upsilon(\sigma(b))+\sum_{p=1}^{P} \alpha_{p} u^{\prime}\left[\left(v_{i}-b\right) \alpha_{p}\right] \Upsilon^{\prime}(\sigma(b)) \sigma^{\prime}(b)
\end{aligned}
$$

Since the second derivative of the utility function is negative, the first summation is positive as long as the bid function is increasing (as assumed). As in lemma 3 we know that $\sum_{p=1}^{P} \alpha_{p} u^{\prime}\left[\left(v_{i}-b\right) \alpha_{p}\right] \Upsilon^{\prime}(\sigma(b))$ consists of all positive parts as long as $\alpha_{p} u^{\prime}\left[\left(v_{i}-b\right) \alpha_{p}\right] \geqslant$ $\alpha_{p+1} u^{\prime}\left[\left(v_{i}-b\right) \alpha_{p+1}\right]$, which is the same condition as under risk neutrality, since there $u^{\prime}(\pi)=$ 1 , and puts a restriction on the size of the contract parts. Note, however, that this condition holds trivially if $\alpha_{1}=1$ and if $\alpha_{p}=\alpha_{p+1}$, so the constraint is not very restrictive. Provided the size of the contracts are chosen reasonably and contracts are ordered in size, we can assume the second summation is positive as well.

So we can conclude that $\frac{\partial U}{\partial v_{i}}$ satisfies the required single crossing property, since its partial cross-derivative is positive, then the monotone comparative statics result (theorem 1)from Milgrom \& Roberts, (1994) ascertains that the bid function is increasing in $v_{i}$. There exists a symmetric equilibrium with a monotonically increasing bid function. 